\title{
Correction to: Comprehension of written texts for the assessment of clinical competence and decision making in people with mild to moderate Alzheimer disease
}

\author{
Valentina Moro ${ }^{1} \cdot$ Valeria Valbusa ${ }^{2} \cdot$ Nicole Corsi $^{3} \cdot$ Annachiara Bonazzi $^{4} \cdot$ Maria Teresa Condoleo $^{2}$. \\ Elisabetta Broggio ${ }^{2} \cdot$ Michele Scandola $^{1}$. Giuseppe Gambina ${ }^{4}$
}

Published online: 16 January 2020

(C) Fondazione Società Italiana di Neurologia 2020

Correction to: Neurological Sciences (2020)

https://doi.org/10.1007/s10072-019-04228-0

The above article was published online with missing author. The additional author is Michele Scandola.

The online version of the original article can be found at https://doi.org/ 10.1007/s10072-019-04228-0

Valentina Moro

valentina.moro@univr.it

1 NPSY.Lab-VR, Department of Human Sciences, University of Verona, Lungadige Porta Vittoria 17, 37129 Verona, Italy

2 Alzheimer's Disease Center, Neurology A University Hospital of Verona, Verona, Italy

3 Department of Neurosciences, Biomedicine and Motor Sciences, University of Verona, Verona, Italy

4 Verona Memory Center, CEMS, Verona, Italy 